\title{
Dairy products and plasma cholesterol levels
}

\author{
Lena Ohlsson'*
}

'Laboratory of Gastroenterology and Nutrition, Department of Clinical Sciences, Medicine, BioMedical Centre BI I, Lund University, Lund, Sweden

Abstract

Cholesterol synthesized in the body or ingested is an essential lipid component for human survival from our earliest life. Newborns ingest about 3-4 times the amount per body weight through mother's milk compared to the dietary intake of adults. A birth level of $1.7 \mathrm{mmol} / \mathrm{L}$ plasma total cholesterol will increase to $4-4.5$ $\mathrm{mmol} / \mathrm{L}$ during the nursing period and continue to increase from adulthood around $40 \%$ throughout life. Coronary artery disease and other metabolic disorders are strongly associated with low-density lipoprotein (LDL) and high-density lipoprotein (HDL) cholesterol as well as triacylglycerol concentration. Milk fat contains a broad range of fatty acids and some have a negative impact on the cholesterol rich lipoproteins. The saturated fatty acids (SFAs), such as palmitic acid (C16:0), myristic acid (C14:0), and lauric acid (C12:0), increase total plasma cholesterol, especially LDL, and constitute $11.3 \mathrm{~g} / \mathrm{L}$ of bovine milk, which is $44.8 \%$ of total fatty acid in milk fat. Replacement of dairy SFA and trans-fatty acids with polyunsaturated fatty acids decreases plasma cholesterol, especially LDL cholesterol, and is associated with a reduced risk of cardiovascular disease. Available data shows different effects on lipoproteins for different dairy products and there is uncertainty as to the impact a reasonable intake amount of dairy items has on cardiovascular risk. The aim of this review is to elucidate the effect of milk components and dairy products on total cholesterol, LDL, HDL, and the LDL/HDL quotients. Based on eight recent randomized controlled trials of parallel or cross-over design and recent reviews it can be concluded that replacement of saturated fat mainly (but not exclusively) derived from high-fat dairy products with low-fat dairy products lowers LDL/HDL cholesterol and total/HDL cholesterol ratios. Whey, dairy fractions enriched in polar lipids, and techniques such as fermentation, or fortification of cows feeding can be used to produce dairy products with more beneficial effects on plasma lipid profile.

Keywords: bovine milk; low-density lipoprotein; high-density lipoprotein; saturated fatty acids; LDL/HDL quotients

Received: 8 March 2010; Revised: 10 June 2010; Accepted: 30 June 2010; Published: 19 August 2010

$\mathrm{C}$ holesterol is an essential lipid component in cell membranes and a precursor of bioactive lipids such as bile acids and steroid hormones. Plasma cholesterol levels are also a well-known risk factor for cardiovascular disease (CVD). Mortality in the Western world is still caused to a high extent by CVD and a large amount of data related to CVD and other metabolic diseases concern our intake of fat. Two types of dietary fatty acids raise plasma cholesterol - saturated fatty acids (SFAs), mainly palmitic acid (C16:0), and trans-fatty acids $(t \mathrm{FAs})$. Epidemiological as well as clinical data have shown that elevated low-density lipoprotein (LDL) cholesterol, especially small dense LDL particles, together with reduced high-density lipoprotein (HDL) cholesterol are associated with the risk of development of CVD. From 60 selected trials, Mensink et al. (1) summarized the effects of dietary fats on total cholesterol to HDL cholesterol ratios and concluded that replacing $t$ FAs with unsaturated fatty acids gives the single most effective improvement in plasma lipids. Also, replacement of SFA with cis-unsaturated fatty acids reduces CVD risk $(2,3)$. One of the oldest and longest dietary intervention studies in the Nordic countries was the North Karelia Project, which started in the early 1970s. The main goal was to reduce the number of cardiovascular deaths by implementing a health promoting program on a large population. A major factor with high impact on this study was the change in intake of fat quality from butter to more unsaturated fat, which led to a $40 \%$ reduction in cholesterol concentrations $(4,5)$. There are prospective cohort studies and reviews (6-9) describing the effect of dairy fat on plasma cholesterol composition and the consensus is that there is no general relation between dairy intake and cardiovascular risk. Therefore, an 
important question is whether a reasonable intake of dairy products in a balanced diet promotes health in other ways that outweigh the cholesterol raising effects. The aim of this review is to report an update on recent results from intervention studies with dairy products and their effects on cholesterol containing lipoproteins, and also to put current knowledge about milk components in relation to effects on plasma cholesterol.

\section{Selection strategy}

This review is primarily based on relevant original articles and recent reviews available in PubMed using the search words 'dairy intake,' 'milk fat,' 'cholesterol,' and 'human,' in combination with 'cardiovascular risk' or 'cardiovascular disease,' published from 2003, but with a focus on the recent 5 years. Additionally selected older publications are included to support the topic. The studies presented in Table 1 are randomized controlled trials performed from 2003 on the effects of different dairy products on plasma lipids with significant outcome.

\section{Neonatal aspects}

Milk is an optimal and natural food for a newborn baby. It is sometimes argued in adult nutrition that milk is a 'natural' food and could therefore not be harmful. Thus, there is reason to comment on the differences in cholesterol metabolism between adults and suckling babies. Cord blood has a different lipoprotein profile compared to adults. It contains one-third of the LDL concentration and one-half of the HDL concentration. At birth, LDL cholesterol and apolipoprotein B (apoB) concentrations are negatively associated with gestational age and total cholesterol concentration is around 1.67 $\mathrm{mmol} / \mathrm{L}$. During the first 5 days of nursing, the cholesterol concentration increases rapidly to the double (10). The following month the composition of LDL particles is modulated by the feeding mode. Both total- and LDLcholesterol concentrations are higher in breastfed babies than formula-fed babies and total cholesterol reaches almost $4 \mathrm{mmol} / \mathrm{L}$ for breastfed babies and around $3.5 \mathrm{mmol} / \mathrm{L}$ for formula-fed babies. The fat content in human milk and also its composition varies during the lactation period, whereas the cholesterol concentration decreases with the stages of lactation $(11,12)$. The daily cholesterol intake of $15-20 \mathrm{mg} / \mathrm{kg}$ is around 3-4 times the corresponding intake for adults. The intake of cholesterol in newborns and probably also the cholesterol synthesis subsequently match the need for cholesterol during rapid organ growth and the expansion of membrane cholesterol pools. Normal levels of plasma cholesterol for children and adolescents aged 2-19 years are 4-5 mmol/L and from 20 to 70 years of age, the plasma cholesterol increases by $30-45 \%$. Subsequently, the need for dietary cholesterol is not the same when bovine milk and dairy products in general become an important part of basic food intake in adolescence and adulthood. It is also worth emphasizing that bovine milk differs from breast milk in that it contains rumen-derived short-chain fatty acids (C4:0-C8:0) - 3.5 times as much calcium and 2.5 times as much proteins - lower concentrations of unsaturated fatty acids and sphingomyelin, and more SFAs $(12,13)$.

\section{Intervention studies}

Numerous intervention studies have been published comparing the cholesterolemic effects of different dairy products on both healthy individuals and individuals with some metabolic disorder. Whereas the results for butter are consentient, trials with milk, fermented products, and cheese are less conclusive. In a study designed to compare the effects of the physical state of milk fat on plasma cholesterol diets providing $20 \mathrm{E} \%$ (of which $16 \mathrm{E} \%$ is SFA) as dairy fat either as whole milk, butter or hard cheese were compared (14) (Table 1). In this strictly controlled cross-over study on 14 healthy young men, they found no support for a hypocholesterolemic milk factor. The cheese diet resulted in 5 and 7\% lower total cholesterol and LDL concentrations compared to butter, possibly as a consequence of the higher amount of calcium and fermentation of cheese. The overall decrease in triglycerides (TG) of 16-20\% after all three diets could be explained by the lower content of carbohydrates compared to their normal diet. Others have obtained similar results (15) (Table 1). In a study by Biong et al. (16) (Table 1), the authors compared intake of cheese with butter enriched with casein or egg protein. The results from this study showed that at equal fat and protein content, cheese decreased total plasma cholesterol by $3 \%$, but the LDL:HDL ratio was not different between the diets. Once again, the calcium content was higher in the cheese diet, which could promote the excretion of fat as calcium soaps. Also, one of the bacterial strains used in the fermentation of the cheese was found to have hypocholesterolemic effects on rats (17). Cheese is still a source of SFA and in a randomized controlled clinical trial with cross-over design, 31 subjects with mild hypercholesterolemia consumed $65 \mathrm{~g}$ of cheese per day made from either milk fat or rapeseed oil (18). After intervention, the total serum cholesterol and LDL cholesterol was reduced by 6.7 and $7 \%$ after 2 weeks and by 5 and $6.4 \%$ after 4 weeks with the rapeseed oilbased cheese. The HDL cholesterol concentrations were not significantly changed. A more recent intervention study undertaken simultaneously in Finland, Norway, and Sweden included 120 men and women with less than two symptoms of the metabolic syndrome (19) (Table 1). In this 6-month randomized parallel-group study the participants were allocated to a milk group or control group. The milk group was instructed to include 3-5 defined portions of dairy products in their daily diet while 
Table 1. The table presents intervention studies in which the aims were to investigate the effects of dairy products on plasma cholesterol concentrations and in which significant changes in cholesterol concentrations were seen

\begin{tabular}{|c|c|c|c|c|}
\hline \multirow{2}{*}{$\begin{array}{l}\text { Reference } \\
\text { Tholstrup et al. [14] }\end{array}$} & \multicolumn{2}{|c|}{$\begin{array}{l}\text { Subjects (men + women) } \\
\text { and intervention time }\end{array}$} & \multirow{2}{*}{$\begin{array}{c}\text { Dairy product (daily intake) } \\
\text { I.5 L milk, } 64 \text { g butter, } 205 \mathrm{~g} \text { cheese }\end{array}$} & \multirow{2}{*}{$\begin{array}{l}\text { Significant effect on plasma } \\
\text { cholesterol }\end{array}$} \\
\hline & 14 men & 3 weeks & & \\
\hline Nestel et al. [15] & $14+5$ & 4 weeks & $40 \mathrm{~g}$ butter or Cheddar cheese & $\begin{array}{l}\text { Total and LDL cholesterol } 9 \text { and } 15 \% \text { higher } \\
\text { after butter }\end{array}$ \\
\hline Biong et al. [16] & $9+13$ & 3 weeks & $150 \mathrm{~g}$ cheese, $52 \mathrm{~g}$ butter + protein & $\begin{array}{l}\text { Total cholesterol } 3 \% \text { lower with cheese vs. } \\
\text { butter meals }\end{array}$ \\
\hline Wennersberg et al. [19] & $4 I+80$ & 6 months & $\begin{array}{l}300 \mathrm{~g} \text { more milk, } 20 \mathrm{~g} \text { more cheese, } \\
5 \mathrm{~g} \text { more butter than controls }\end{array}$ & $\begin{array}{l}\text { Total cholesterol } 4 \% \text { higher in dairy group vs. } \\
\text { control }\end{array}$ \\
\hline Motard-Bélanger et al. [40] & 48 men & 4 weeks & $\begin{array}{l}\text { Ruminant } t \mathrm{FA} \text { high }(10.2 \mathrm{~g} / 2,500 \mathrm{kcal}) \\
\text { or moderate }(4.2 \mathrm{~g} / 2,500 \mathrm{kcal}) \text {, } \\
\text { industrial } t \mathrm{FA} \text { high or low }(2.2 \mathrm{~g} / \\
2,500 \mathrm{kcal}) t \mathrm{FA}\end{array}$ & $\begin{array}{l}\text { Total and LDL cholesterol increased } 3 \text { and } 2 \% \\
\text { with high ruminant } t \mathrm{FA} \text { and } 6 \text { and } 5 \% \text { with } \\
\text { industrial } t \mathrm{FA} \text { vs. control }\end{array}$ \\
\hline Chardigny et al. [38] & $19+21$ & 3 weeks & $\begin{array}{l}\text { Butter or cheese for ruminant } t \mathrm{FA} \text {, } \\
\text { cookies for industrial } t \mathrm{FA} .4 \% \text { of daily } \\
\text { energy } 67 \% \text { of daily fat energy }\end{array}$ & $\begin{array}{l}\text { In women: } \mathrm{HDL} \text { cholesterol } 6 \% \text { lower with } \\
\text { industrial } t \mathrm{FA} \text { vs. ruminant } t \mathrm{FA} \text {. LDL was } 15 \% \\
\text { higher with ruminant } t \mathrm{FA} \text {.Total cholesterol } \\
\text { II\% increased with ruminant } t \mathrm{FA}\end{array}$ \\
\hline Andrade et al. [74] & 34 women & 4 weeks & $\begin{array}{l}\text { I } 25 \mathrm{~g} \times 3 \text { fermented milk or plain } \\
\text { yoghurt }\end{array}$ & $\begin{array}{l}\text { Decrease of LDL (12,5 and 16\%). Also } \\
\text { decrease HDL 10-12\% }\end{array}$ \\
\hline Seidel et al. [77] & $16+15$ & 13 weeks & $\begin{array}{l}\text { (a) } 250 \mathrm{~g} \text { regular milk, } 150 \mathrm{~g} \text { regular } \\
\text { yoghurt and butter for cooking, (b) the } \\
\text { same as a with modified milk, or (c) } \\
\text { same as a with margarine }\end{array}$ & $\begin{array}{l}\text { HDL increased I5\%. LDL and LDL/HDL } \\
\text { decreased } 11 \% \text { and } 17.5 \% \text { after modified milk }\end{array}$ \\
\hline
\end{tabular}

the control group continued with their habitual diet. The dairy group consumed $300 \mathrm{~g}$ more milk or yoghurt, $20 \mathrm{~g}$ more cheese and $5 \mathrm{~g}$ more butter than control group. The result was a moderate increase of $4 \%$ in serum total cholesterol in the milk group compared to control. A moderate increase in apoB in the milk group, especially in Sweden, was positively associated with the increase in C15:0, a biomarker of milk fat. The explanation might be the intake of more full-fat dairy products in the Swedish participants, whereas Norwegian and Finnish participants ate preferably low- to moderate-fat products (19).

Butter affects postprandial lipemia differently compared to vegetable oils. When $42-50 \mathrm{~g}$ of butter in a meal was compared with $35-40 \mathrm{~g}$ of olive oil, postprandial TG was lower with butter $(20,21)$ and in another study the size of the chylomicrons were smaller (22). This was seen both in healthy subjects and in overweight persons with non-insulin-dependent diabetes. By contrast, after-meals containing $100 \mathrm{~g}$ of butter compared with $80 \mathrm{~g}$ of olive oil, the postprandial TG concentrations are higher and the HDL cholesterol lower with butter both in healthy and type 2 diabetic individuals $(23,24)$. Whereas the presence of short-chain fatty acids in butter commonly explains the lower increase in postprandial plasma lipids in relation to other oils, the opposite relation occurring at a high lipid load has not been unraveled.

\section{Factors in dairy products that affect plasma cholesterol}

Milk contains a large number of bioactive compounds, but milk fat has the largest impact on plasma lipids. The lipid pattern in dairy fat is very complicated and more than 400 different fatty acids have been identified. About $70 \%$ of dairy fat contains SFAs of which the majority $(45 \%)$ are of $12-16$ carbon chain length and $2.7 \%$ are $t$ FAs (13), and these have the ability to raise plasma cholesterol. Except for the concentration of different types of plasma lipoproteins that can be affected, their size and composition will change in response to different types of dietary fat. For example, it is suggested that larger sizes of lipoproteins are less atherogenic than smaller sizes (25) and some of the fatty acids typically found in milk fat have been associated with less dense LDL particles (26).

Other milk components like proteins, calcium, and lactose have been suggested to affect lipid metabolism directly or indirectly, but the strongest impact on plasma lipids emerges from the intake of milk fat. 


\section{Saturated fatty acids (SFA)}

After absorption, the predominant dairy SFA palmitic acid (C16:0), but also myristic acid (C14:0) and lauric acid $(\mathrm{C} 12: 0)$ are preferentially directed to TG formation rather than to phospholipid acylation. These three longchain fatty acids raise total cholesterol, but their effects on LDL:HDL ratios are different. Palmitic acid is the major SFA in the diet and also in milk fat with a content of about $30 \%$. Palmitic acid raises the LDL cholesterol more than it raises HDL cholesterol (27). Myristic acid represents $11 \%$ of the dairy fatty acids and increase total cholesterol as much as palmitic acid, but does not affect total cholesterol:HDL ratio $(1,28)$. Lauric acid is the most potent fatty acid in raising plasma total cholesterol, but dairy content is only $3.3 \%$. The increase in HDL cholesterol induced by lauric acid is higher than the increase in LDL and thus the total cholesterol:HDL ratio was decreased when lauric acid was used to replace carbohydrates (1). Stearic acid represents $12 \%$ of the dairy fatty acids and improves the plasma cholesterol profile by decreasing total/HDL cholesterol ratio compared to other SFAs. But compared to polyunsaturated fatty acids (PUFA), stearic acid increases LDL and decreases HDL and increase total/ HDL ratio (29). Other SFAs are short- and medium-chain length and are mainly considered to be cholesterol neutral. At a certain amount of SFA intake, an increase in both LDL and HDL cholesterol can be seen, especially if the intake of unsaturated fatty acids is low $(30,31)$. In a recent metaanalysis of prospective epidemiological studies, intake of SFA and risk of CVD was studied (32). Six studies found a significant positive association between SFA intake and CVD, and 10 studies found no significant association. The author states, however, that there is a need for further studies to evaluate the CVD risks when replacing SFA with other specific nutrients.

The outcome of the meta-analysis (32) does not differ between men and women, but there are studies included suggesting that men and women have a different risk ratio from consumption of SFA with a slightly higher risk for men (33). In a recent meta-analysis of randomized controlled trials the pooled results from eight trials demonstrated a significant reduction in CVD events by replacing SFA with PUFA (34). In summary, if the target is to reduce plasma cholesterol, especially LDL, the intake of SFAs from dairy and other products should be replaced by low-fat dairy products or PUFA.

\section{Unsaturated fatty acids}

Although unsaturated fatty acids are a minor component of milk fat, monounsaturated fatty acids (MUFA), such as oleic acid (C18:1), is the second most abundant fatty acid representing $23 \%$ by weight in Swedish dairy milk (13). Dairy products together with meat and hydrogenated oils are actually a major source of MUFA in
Scandinavia. Oleic acid is considered favorable since it has a cholesterol- and TG-lowering effect compared with SFA, and meals containing olive oil increase the size of postprandial TG-rich lipoproteins more than meals with butter (35), which is considered to be less atherogenic. By increasing MUFA at the expense of SFA, which can be done with modification of dairy products, larger postprandial chylomicrons can be formed (36). The overall effect of MUFA from dairy products is, however, not clear since the intake of oleic acid from other dietary products is high.

\section{Trans-fatty acids (tFA)}

Of the seasonal variation of fat in bovine milk, $t$ FA have the largest variation and their concentrations are more than twice as high in summer milk as in winter milk (37), e.g. the variation in Swedish cows is from 0.6 to $3.9 \%$ with an approximate medium value of $2.7 \%$ (13). The dietary $t \mathrm{FA}$ of industrial origin that humans consume from eating cookies, pastries, and microwave popcorn are shown in many studies to be detrimental to our vascular health $(38,39)$. Milk fat is the major source of natural conjugated linoleic acid (CLA) and the predominant isoform is cis-9, trans-11 CLA, which accounts for $85-90 \%$. The minor trans-10, cis-12 CLA isomer has been shown to have a more detrimental effect on plasma cholesterol than cis-9, trans-11 CLA since it increases total/HDL and LDL/HDL ratios. The effect of natural $t$ FA, such as CLA and trans $18: 1$, found in dairy products and meat and of industrial $t \mathrm{FA}$ on human plasma lipids has been investigated. The study by Motard-Belanger et al. (40) suggests that ruminant $t$ FA have little impact on cholesterol homeostasis (Table 1). In this 4-week randomized, cross-over-controlled study on 38 healthy men, they found that a moderate intake of ruminant $t \mathrm{FA}$ had neutral effects on plasma lipids, whereas high amounts of both ruminant and industrial $t$ FA increased both the total plasma cholesterol by 3 and $2 \%$, respectively, and LDL cholesterol by 6 and $4.6 \%$. In a quantitative review of 39 carefully selected original articles, only including randomized controlled trials in a parallel or cross-over design, the authors conclude that all $t \mathrm{FA}$ increases the LDL/HDL ratio in a linear fashion (41). The effect of ruminant $t \mathrm{FA}$ and CLA on the LDL/ HDL ratio was less than that of industrial $t$ FA. In the TRANSFACT study, a randomized controlled trial, 46 healthy subjects consumed 11-12 g/day of either industrial or ruminant $t$ FA (38) (Table 1). The major finding was that the natural sources of $t \mathrm{FA}$ significantly increases HDL- and LDL-cholesterol concentrations in women but not in men, and the HDL-lowering effect is mainly associated with industrial $t$ FA. The differences in cholesterol concentrations observed in women were also associated with the size of lipoproteins and $t \mathrm{FA}$ from natural sources increases the proportion of larger 
particles. Thus, reducing the intake of ruminant fat will decrease the plasma cholesterol concentration and an improvement of the LDL/HDL ratio is likely. The mechanisms underlying the gender effects and type of isoforms need further investigation.

\section{Medium-chain fatty acids (MCFA)}

Medium-chain fatty acids (MCFA) are caproic acid (hexanoic acid, C6:0), caprylic acid (octanoic acid, C8:0), and capric acid (decanoic acid, C10:0). MCFA are present at about $6.8,6.9,6.6$, and $7.3 \%$ (of total fatty acid) in butter, milk, yogurt, and cheese, respectively (42). MCFA are rapidly hydrolyzed in the gastrointestinal tract (GI-tract) and are directly transported to the liver and into the mitochondria of the hepatocytes for oxidation (43) but some, especially decanoic acid (C10:0) will be incorporated to chylomicron TG. Several studies report effects such as increased lipid oxidation, decreased body weight, increased thermogenesis and energy expenditure from consumption of MCFA and a few studies report a lowering of total cholesterol, LDL, and an increase of LDL particle size $(44,45)$. Whether the long-term effects on plasma cholesterol levels and an improvement of LDL:HDL ratios are caused by weight reduction or are an actual effect of the MCFA itself is not fully clarified. In a randomized controlled intervention study on 17 healthy individuals, a high intake of $70 \mathrm{~g}$ of MCFA per day for 3 weeks was, however, detrimental to plasma lipids with a $12 \%$ increase both in LDL cholesterol and LDL/HDL ratio (46). In another study, intake of moderate amounts (10 E\%) of MCFA for 6 weeks had no effect on plasma cholesterol concentrations (47). The intake of MCFA from dairy products will be of little significance with regard to concentration, whereas the interaction with other dairy lipid components might have an effect on plasma lipids, but no such data are available.

\section{Polar lipids}

The milk fat globule membrane contains $2-3 \%$ of polar lipids, mostly phosphatidylcholine (PC) (30-35\%), but also sphingomyelin $(25 \%)$. Some studies showed that human milk has higher levels of sphingomyelin (SM) than of PC (11). In a Western diet, the intake of SM

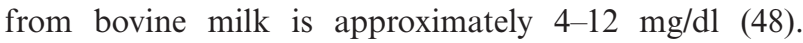
Studies on rats and mice have shown that dietary SM from milk inhibits cholesterol absorption (49-51). We recently performed a 4-week intervention study on 48 healthy subjects where participants consumed a sphingomyelin-enriched milk drink every day with their habitual diet. Our main hypothesis of a cholesterol-lowering effect was unconfirmed but there was a trend that the SMenriched drink counteracted the effects emerging from an increased energy intake. The increased plasma concentra- tions of cholesterol and TG caused by the elevated energy intake, mainly caused by the test drinks, were counteracted by the SM-enriched drink (52). There are several potential mechanisms by which dairy products enriched in polar lipids can promote vascular health and reduce risk, such as affecting the cholesterol absorption and being a source of unsaturated fatty acids. Presently, there are only few studies within this area and human intervention trials are warranted.

\section{Proteins}

There are studies supporting the hypothesis that dairy products have anti-obesity effects and the bioactive compounds such as calcium and proteins augmenting this effect have been discussed $(53,54)$. In the 1990s, it was suggested that whey proteins had more hypocholesterolemic effect than casein and soy proteins in rats $(55,56)$. A decade later, four peptides formed from tryptic cleavage of bovine $\beta$-lactoglobulin: IIAEK, GLDIQK, ALPMH, and VYVEELKPTPEGDLEILLQK were found to inhibit cholesterol absorption by increasing fecal output of steroid. Of the four peptides, IIAEK had a higher effect than $\beta$-sitosterol (57). In a recent in vitro study on a human intestinal cell line (NCI-H716), the effects both of the specific amino acids leucine, isoleucine and valine, and of whey, skim milk and casein on expression of lipidregulating genes was examined (58). It was found that isoleucine, leucine, valine, and whey down-regulated Niemann-Pick C1-like 1 (NPC1L1), a protein carrier with a critical role for intestinal cholesterol absorption. They conclude that dairy products such as whey, with a high content of branched-chain amino acids can have an effect on cholesterol absorption and possibly also on the plasma cholesterol concentration. The hypocholesterolemic effect of whey has now been confirmed also in humans (59). A comparison of whey proteins and casein with glucose as control was recently conducted on overweight/ obese subjects. After 12 weeks of daily intake, results showed that whey significantly decreased total and LDL cholesterol compared to both casein and control. Furthermore, Nyberg et al. (60) found evidence of an acid sphingomyelinase present in human milk, which may generate ceramide from hydrolysis of milk SM in the stomach, and recent investigations in human intestinal Caco-2 cells showed that the presence of ceramide inhibited the cellular uptake of cholesterol more effectively than that of SM (61). Taken together, whey proteins but not casein seems to have hypocholesterolemic effects by inhibiting intestinal absorption of cholesterol. Whether acid sphingomyelinase is present in bovine milk and, if so, has any effect on digestion of dairy SM in the stomach is not known. 


\section{Calcium}

Calcium as a food supplement has been shown to increase HDL cholesterol and decrease total- and LDL-cholesterol concentrations, thereby improve the HDL:LDL ratio (6264). Dairy products are the richest source of calcium and the concentration is highest in hard cheese. It was shown in an intervention study on 18 healthy men that milk and yoghurt containing different concentrations of calcium decreased postprandial lipid response in a dose-dependent manner (65). The results by Lorenzen et al. (65) and from other trials (66) indicate that an increase in dairy calcium promotes fecal fat excretion, but support as to whether this affects plasma cholesterol concentrations is lacking.

\section{Lactose}

It is hypothesized that lactose can affect lipemia by promoting calcium absorption. In humans, it has been hypothesized whether lactose is a risk factor for ischemic heart disease (IHD) in a study based on data from 43 countries (67). The study compares populations with different grades of lactose malabsorption and milk intake. They propose that there is a correlation between populations with high occurrence of lactose malabsorption and lower incidence of mortality from IHD. This is, however, contradicted in several studies where the risk ratios for myocardial infarctions are $<1$ with a high milk consumption $(68,69)$. In older human studies, ingesting $80 \mathrm{~g}$ of lactose per day as whey resulted in a decreased serum cholesterol (70). Furthermore, $50 \mathrm{~g} /$ day of added lactose to patients with CVD significantly reduced serum cholesterol over a 3-week period (71). In a study comparing high-fatfed mice with mice fed both high-fat and lactose, plasma lipids were significantly lower in the group fed high fat with lactose. The body weight gain was also slightly lower for mice-fed lactose, but cholesterol levels were not investigated (72). There seems to be no newer human data on plasma cholesterol after intake of lactose-free dairy products compared to the lactose-containing counterparts.

\section{Fermented dairy products}

The effects of fermented dairy products have been studied since the 1970s. The first studies showed that unpasteurized yoghurt decreased serum cholesterol by 5-9\%. Later, results from some studies showed no effects of fermented products, but this was explained by the fact that the subjects in the study had a baseline cholesterol concentration of $<5.0 \mathrm{mmol} / \mathrm{L}$. Since then, many studies have displayed hypocholesterolemic effects on hypercholesterolemic subjects (73). In a recent study on 34 women, an intake of $125 \mathrm{~g}$ of fermented milk three times a day for 4 weeks decreased plasma LDL cholesterol by $12.5-16 \%$. There was also a significant decrease of HDL cholesterol of $10-12 \%$ (74) (Table 1). It is concluded that many strains of fermentation bacteria, but not all are viable enough to reach the lower part of the gut and exert effects on the microbiota, thereby increasing the amount of propionate that has a cholesterol-lowering effect. The second effect by which bacteria may influence cholesterol level is by hydrolyzing glycine and taurin-conjugated bile acids $(15,75)$. By deconjugating bile acids, the excretion of bile acids in feces is increased, which promote the use of cholesterol for synthesis of new bile acids. The use of fermented milk instead of normal milk may therefore be a method to reduce or maintain the plasma cholesterol levels, but the effects on LDL/HDL ratio should be further investigated.

\section{Modified dairy products}

Of the main milk components, fat is the most sensitive to dietary changes (76). Except for seasonal variations in bovine milk fat composition, fortified feeding of cows may affect the milk fat composition. By feeding cows 400 $\mathrm{g}$ of rapeseed oil, Seidel et al. (77) were able to reduce SFA (C12:0, C14:0, and C16:0) by 20\% and increase the milk content of unsaturated fatty acids by about $33 \%$. In the following intervention study divided into three periods of 18 days each, both normo- and hyperlipidemic subjects increased their HDL cholesterol and reduced the LDL cholesterol after the period with modified milk. This was not seen after periods with regular fat or margarine (77) (Table 1). In this study, normolipidemic subjects responded more sensitively to changes in HDL and LDL cholesterol than those with hyperlipemia. By modification of cow-feeding regimes, the fatty acid composition of milk might be adjusted to contain less SFA and consequently more healthy dairy products can be produced.

\section{Conclusion}

The impact on our plasma lipid levels from dairy intake is depending on amounts, fat concentrations, and also on gender, age, and metabolic capacity of the consumer. Certain dairy products are also often part of a healthconscious lifestyle, which promotes maintaining or loss of weight with a subsequent improvement of plasma cholesterol profile. Also, when it comes to choices of food within the same group, women tend to choose low-fat dairy products more often than men do.

Despite the complexity of this nutrient, we find some conclusions that can be made regarding milk fat and cholesterol.

Dairy fat contains a high concentration of SFA and since dairy products are a considerable part of habitual diets, they have also generally been a target for restriction advice in order to reduce intake of saturated fat. Intake of saturated fat with chain length $\mathrm{C} 12-\mathrm{C} 16$ and $t \mathrm{FA}$ increases plasma LDL which is an independent risk factor for CVD. The presence of $t \mathrm{FA}$ in dairy fat increases the LDL/HDL linearly with dose and, theoretically, by lowering the $t \mathrm{FA}$ intake by $0.5 \%$ of energy, this might reduce 
the cardiovascular risk by $1.5-6 \%$. Palmitic acid is the predominant fatty acid in milk fat and increases the LDL:HDL ratio more than lauric and myristic acids do. It can be calculated how much a change in SFA intake will affect the LDL cholesterol and the risk of developing CVD. By substituting $30 \mathrm{~g}$ of butter per day containing about $11 \mathrm{~g}$ of SFA with a margarine rich in unsaturated fatty acids containing $2.4 \mathrm{~g}$ of SFA, would reduce LDL cholesterol by $0.2 \mathrm{mmol} / \mathrm{L}$ and subsequently reduce the risk of CVD in the order of 6-10\%. In light of this, the increase of $4.9 \mathrm{~g} /$ day SFA intake in the milk group in the study by Wennersberg resulted in a slight increase in LDL cholesterol of $0.1 \mathrm{mmol} / \mathrm{L}$. In some cohorts with a rather high baseline intake of dairy fat, correlations between dairy intake and plasma cholesterol would therefore be scarce. However, dairy SFA is not only $\mathrm{C} 12-\mathrm{C} 16$, but around $25 \%$ is represented by short- and medium-chain fatty acids, which have the ability to affect the digestion of milk fat already in the stomach through digestion by gastric lipase and isomerization of fatty acids in the partially hydrolyzed TG. It is necessary to distinguish between the effects of butter and other dairy products, since butter increases plasma cholesterol, especially LDL cholesterol, more than other dairy products. Dairy fat raises both LDL and HDL cholesterol, but the evidence for a detrimental effect of high plasma LDL levels is stronger than the positive effects from an increased HDL concentration. Intervention studies that focus on reducing dairy fat intake and other studies as well, must be aware of the effect on HDL cholesterol, both regarding size and concentration, since a reduction in HDL size and concentration may not improve health or reduce CVD risks.

On the basis of controlled and randomized dietary intervention studies with different dairy products and recent meta-analyses of both epidemiological and controlled studies, the present approach to limit the intake of high-fat dairy products on behalf of low-fat products is unchallenged. A reasonable intake of cheese, low-fat and fermented milk reduced plasma cholesterol levels, mainly LDL cholesterol, in the order of $3-15 \%$ compared to butter or other high-fat dairy products, but not compared to nutrients containing more PUFA. The levels of milk components, e.g. MUFA, MCFA, and other polar lipids, have little individual impact on plasma cholesterol concentrations, but there are only few studies for consensus and no studies on concerted action of selected components. There is still no satisfactory explanation for the term 'milk factor,' although some unknown mechanism might yet be found in the interaction between calcium, proteins, lactose, and fatty acids.

\section{Conflicts of interest}

The author declares no conflict of interest regarding this review.

\section{References}

1. Mensink RP, Zock PL, Kester AD, Katan MB. Effects of dietary fatty acids and carbohydrates on the ratio of serum total to HDL cholesterol and on serum lipids and apolipoproteins: a meta-analysis of 60 controlled trials. Am J Clin Nutr 2003; 77: $1146-55$.

2. Jakobsen MU, O'Reilly EJ, Heitmann BL, Pereira MA, Balter $\mathrm{K}$, Fraser GE, et al. Major types of dietary fat and risk of coronary heart disease: a pooled analysis of 11 cohort studies. Am J Clin Nutr 2009; 89: 1425-32.

3. Harris WS, Miller M, Tighe AP, Davidson MH, Schaefer EJ. Omega-3 fatty acids and coronary heart disease risk: clinical and mechanistic perspectives. Atherosclerosis 2008; 197: 12-24.

4. Puska P, Tuomilehto J, Salonen J, Neittaanmaki L, Maki J, Virtamo J, et al. Changes in coronary risk factors during comprehensive five-year community programme to control cardiovascular diseases (North Karelia project). Br Med J 1979; 2: 1173-8.

5. Puska P. Fat and heart disease: yes we can make a change - the case of North Karelia (Finland). Ann Nutr Metab 2009; 54: 33-8.

6. Elwood PC, Pickering JE, Fehily AM. Milk and dairy consumption, diabetes and the metabolic syndrome: the Caerphilly prospective study. J Epidemiol Community Health 2007; 61: 695-8.

7. Nestel PJ. Effects of dairy fats within different foods on plasma lipids. J Am Coll Nutr 2008; 27: 735S-40S.

8. German JB, Gibson RA, Krauss RM, Nestel P, Lamarche B, van Staveren WA, et al. A reappraisal of the impact of dairy foods and milk fat on cardiovascular disease risk. Eur J Nutr 2009; 48: 191-203.

9. Gibson RA, Makrides M, Smithers LG, Voevodin M, Sinclair AJ. The effect of dairy foods on CHD: a systematic review of prospective cohort studies. Br J Nutr 2009; 102: 1267-75.

10. Fujita H, Okada T, Inami I, Makimoto M, Hosono S, Minato $\mathrm{M}$, et al. Low-density lipoprotein profile changes during the neonatal period. J Perinatol 2008; 28: 335-40.

11. Bitman J, Wood DL, Mehta NR, Hamosh P, Hamosh M. Comparison of the phospholipid composition of breast milk from mothers of term and preterm infants during lactation. Am J Clin Nutr 1984; 40: 1103-19.

12. Jensen RG. The lipids in human milk. Prog Lipid Res 1996; 35: 53-92.

13. Lindmark-Månsson H, Fondén R, Pettersson HE. Composition of Swedish dairy milk. Int Dairy J 2003; 13: 409-25.

14. Tholstrup T, Hoy CE, Andersen LN, Christensen RD, Sandstrom B. Does fat in milk, butter and cheese affect blood lipids and cholesterol differently? J Am Coll Nutr 2004; 23: 169-76.

15. Nestel PJ, Chronopulos A, Cehun M. Dairy fat in cheese raises LDL cholesterol less than that in butter in mildly hypercholesterolaemic subjects. Eur J Clin Nutr 2005; 59: 1059-63.

16. Biong AS, Muller H, Seljeflot I, Veierod MB, Pedersen JI. A comparison of the effects of cheese and butter on serum lipids, haemostatic variables and homocysteine. Br J Nutr 2004; 92: 791-7.

17. Hajime N, Yutaka S, Tetsuji H. Cholesterol lowering activity of ropy fermented milk. J Food Sci 1992; 57: 1327-9.

18. Karvonen HM, Tapola NS, Uusitupa MI, Sarkkinen ES. The effect of vegetable oil-based cheese on serum total and lipoprotein lipids. Eur J Clin Nutr 2002; 56: 1094-101.

19. Wennersberg MH, Smedman A, Turpeinen AM, Retterstol K, Tengblad S, Lipre E, et al. Dairy products and metabolic effects in overweight men and women: results from a 6-mo intervention study. Am J Clin Nutr 2009; 90: 960-8. 
20. Rasmussen O, Lauszus FF, Christiansen C, Thomsen C, Hermansen K. Differential effects of saturated and monounsaturated fat on blood glucose and insulin responses in subjects with non-insulin-dependent diabetes mellitus. Am J Clin Nutr 1996; 63: 249-53.

21. Svensson JR, A. Adlercreutz, P. Nilsson, Å. Ohlsson, L. The postprandial lipemic response to an alpha-linolenic acid rich oil in healthy men. A comparison with butter and olive oil. Metabolism submitted.

22. Mekki N, Charbonnier M, Borel P, Leonardi J, Juhel C, Portugal $\mathrm{H}$, et al. Butter differs from olive oil and sunflower oil in its effects on postprandial lipemia and triacylglycerol-rich lipoproteins after single mixed meals in healthy young men. J Nutr 2002; 132: 3642-9.

23. Thomsen C, Storm H, Holst JJ, Hermansen K. Differential effects of saturated and monounsaturated fats on postprandial lipemia and glucagon-like peptide 1 responses in patients with type 2 diabetes. Am J Clin Nutr 2003; 77: 605-11.

24. Thomsen C, Rasmussen O, Lousen T, Holst JJ, Fenselau S, Schrezenmeir J, et al. Differential effects of saturated and monounsaturated fatty acids on postprandial lipemia and incretin responses in healthy subjects. Am J Clin Nutr 1999; 69: $1135-43$.

25. Kawakami A, Yoshida M. Remnant lipoproteins and atherogenesis. J Atheroscler Thromb 2005; 12: 73-6.

26. Sjogren P, Rosell M, Skoglund-Andersson C, Zdravkovic S, Vessby B, de Faire U, et al. Milk-derived fatty acids are associated with a more favorable LDL particle size distribution in healthy men. J Nutr 2004; 134: 1729-35.

27. Grundy SM. Influence of stearic acid on cholesterol metabolism relative to other long-chain fatty acids. Am J Clin Nutr 1994; 60: 986S-90S.

28. Fernandez ML, West KL. Mechanisms by which dietary fatty acids modulate plasma lipids. J Nutr 2005; 135: 2075-8.

29. Hunter JE, Zhang J, Kris-Etherton PM. Cardiovascular disease risk of dietary stearic acid compared with trans, other saturated, and unsaturated fatty acids: a systematic review. Am J Clin Nutr 2010; 91: 46-63.

30. Hayes KC, Khosla P. Dietary fatty acid thresholds and cholesterolemia. FASEB J 1992; 6: 2600-7.

31. Lecerf JM. Fatty acids and cardiovascular disease. Nutr Rev 2009; 67: 273-83.

32. Siri-Tarino PW, Sun Q, Hu FB, Krauss RM. Meta-analysis of prospective cohort studies evaluating the association of saturated fat with cardiovascular disease. Am J Clin Nutr 2010; 91: $535-46$.

33. Leosdottir M, Nilsson PM, Nilsson JA, Berglund G. Cardiovascular event risk in relation to dietary fat intake in middleaged individuals: data from The Malmo Diet and Cancer Study. Eur J Cardiovasc Prev Rehabil 2007; 14: 701-6.

34. Mozaffarian D, Micha R, Wallace S. Effects on coronary heart disease of increasing polyunsaturated fat in place of saturated fat: a systematic review and meta-analysis of randomized controlled trials. PLoS Med 2010; 7: e100025.

35. Perez-Martinez P, Ordovas JM, Garcia-Rios A, Delgado-Lista J, Delgado-Casado N, Cruz-Teno C, et al. Consumption of diets with different type of fat influences triacylglycerols-rich lipoproteins particle number and size during the postprandial state. Nutr Metab Cardiovasc Dis 2009.

36. Silva KD, Kelly CN, Jones AE, Smith RD, Wootton SA, Miller GJ, et al. Chylomicron particle size and number, factor VII activation and dietary monounsaturated fatty acids. Atherosclerosis 2003; 166: 73-84.

37. Heck JM, van Valenberg HJ, Dijkstra J, van Hooijdonk AC. Seasonal variation in the Dutch bovine raw milk composition. J Dairy Sci 2009; 92: 4745-55.
38. Chardigny JM, Destaillats F, Malpuech-Brugere C, Moulin J, Bauman DE, Lock AL, et al. Do trans fatty acids from industrially produced sources and from natural sources have the same effect on cardiovascular disease risk factors in healthy subjects? Results of the trans Fatty Acids Collaboration (TRANSFACT) study. Am J Clin Nutr 2008; 87: 558-66.

39. Mozaffarian D, Aro A, Willett WC. Health effects of trans-fatty acids: experimental and observational evidence. Eur J Clin Nutr 2009; 63: S5-21.

40. Motard-Belanger A, Charest A, Grenier G, Paquin P, Chouinard Y, Lemieux S, et al. Study of the effect of trans fatty acids from ruminants on blood lipids and other risk factors for cardiovascular disease. Am J Clin Nutr 2008; 87: 593-9.

41. Brouwer IA, Wanders AJ, Katan MB. Effect of animal and industrial trans fatty acids on HDL and LDL cholesterol levels in humans - a quantitative review. PLoS One 2010; 5: e9434.

42. Nagao K, Yanagita T. Medium-chain fatty acids: functional lipids for the prevention and treatment of the metabolic syndrome. Pharmacol Res 2010; 61: 208-12.

43. Aoyama T, Nosaka N, Kasai M. Research on the nutritional characteristics of medium-chain fatty acids. J Med Invest 2007; 54: $385-8$.

44. Bourque C, St-Onge MP, Papamandjaris AA, Cohn JS, Jones PJ. Consumption of an oil composed of medium chain triacyglycerols, phytosterols, and N-3 fatty acids improves cardiovascular risk profile in overweight women. Metabolism 2003; 52: 771-7.

45. Liu Y, Wang J, Zhang R, Zhang Y, Xu Q, Zhang J, et al. A good response to oil with medium- and long-chain fatty acids in body fat and blood lipid profiles of male hypertriglyceridemic subjects. Asia Pac J Clin Nutr 2009; 18: 351-8.

46. Tholstrup T, Ehnholm C, Jauhiainen M, Petersen M, Hoy CE, Lund $\mathrm{P}$, et al. Effects of medium-chain fatty acids and oleic acid on blood lipids, lipoproteins, glucose, insulin, and lipid transfer protein activities. Am J Clin Nutr 2004; 79: 564-9.

47. Temme EH, Mensink RP, Hornstra G. Effects of medium chain fatty acids (MCFA), myristic acid, and oleic acid on serum lipoproteins in healthy subjects. J Lipid Res 1997; 38: 1746-54.

48. Graves EL, Beaulieu AD, Drackley JK. Factors affecting the concentration of sphingomyelin in bovine milk. J Dairy Sci 2007; 90: 706-15.

49. Nyberg L, Duan RD, Nilsson A. A mutual inhibitory effect on absorption of sphingomyelin and cholesterol. J Nutr Biochem 2000; 11: 244-9.

50. Nilsson A, Duan RD. Absorption and lipoprotein transport of sphingomyelin. J Lipid Res 2006; 47: 154-71.

51. Noh SK, Koo SI. Milk sphingomyelin is more effective than egg sphingomyelin in inhibiting intestinal absorption of cholesterol and fat in rats. J Nutr 2004; 134: 2611-6.

52. Ohlsson L, Burling H, Nilsson A. Long term effects on human plasma lipoproteins of a formulation enriched in butter milk polar lipid. Lipids Health Dis 2009; 8: 44.

53. Zemel MB. The role of dairy foods in weight management. J Am Coll Nutr 2005; 24: 537S-46S.

54. Hall WL, Millward DJ, Long SJ, Morgan LM. Casein and whey exert different effects on plasma amino acid profiles, gastrointestinal hormone secretion and appetite. Br J Nutr 2003; 89: 239-48.

55. Nagaoka S, Kanamaru Y, Kuzuya Y. Effects of whey-protein and casein on the plasma and liver lipids in rats. Agric Biol Chem 1991; 55: 813-8.

56. Nagaoka S, Kanamaru Y, Kuzuya Y, Kojima T, Kuwata T. Comparative studies on the serum-cholesterol lowering action of whey-protein and soy-protein in rats. Biosci Biotechnol Biochem 1992; 56: 1484-5. 
57. Nagaoka S, Futamura Y, Miwa K, Awano T, Yamauchi K, Kanamaru Y, et al. Identification of novel hypocholesterolemic peptides derived from bovine milk beta-lactoglobulin. Biochem Biophys Res Commun 2001; 281: 11-7.

58. Chen Q, Reimer RA. Dairy protein and leucine alter GLP-1 release and mRNA of genes involved in intestinal lipid metabolism in vitro. Nutrition 2009; 25: 340-9.

59. Pal S, Ellis V, Dhaliwal S. Effects of whey protein isolate on body composition, lipids, insulin and glucose in overweight and obese individuals. Br J Nutr 2010; Apr 9: 1-8. [Epub ahead of print]

60. Nyberg L, Farooqi A, Blackberg L, Duan RD, Nilsson A, Hernell O. Digestion of ceramide by human milk bile salt-stimulated lipase. J Pediatr Gastroenterol Nutr 1998; 27: 560-7.

61. Feng D, Ohlsson L, Ling W, Nilsson A, Duan RD. Generating ceramide from sphingomyelin by alkaline sphingomyelinase in the gut enhances sphingomyelin-induced inhibition of cholesterol uptake in Caco-2 cells. Dig Dis Sci 2010 (in press).

62. Reid IR, Mason B, Horne A, Ames R, Clearwater J, Bava U, et al. Effects of calcium supplementation on serum lipid concentrations in normal older women: a randomized controlled trial. Am J Med 2002; 112: 343-7.

63. Ditscheid B, Keller S, Jahreis G. Cholesterol metabolism is affected by calcium phosphate supplementation in humans. J Nutr 2005; 135: 1678-82.

64. Shahkhalili Y, Murset C, Meirim I, Duruz E, Guinchard S, Cavadini C, et al. Calcium supplementation of chocolate: effect on cocoa butter digestibility and blood lipids in humans. Am J Clin Nutr 2001; 73: 246-52.

65. Lorenzen JK, Nielsen S, Holst JJ, Tetens I, Rehfeld JF, Astrup A. Effect of dairy calcium or supplementary calcium intake on postprandial fat metabolism, appetite, and subsequent energy intake. Am J Clin Nutr 2007; 85: 678-87.

66. Christensen R, Lorenzen JK, Svith CR, Bartels EM, Melanson EL, Saris WH, et al. Effect of calcium from dairy and dietary supplements on faecal fat excretion: a meta-analysis of randomized controlled trials. Obes Rev 2009; 10: 475-86.

67. Segall JJ. Hypothesis: is lactose a dietary risk factor for ischaemic heart disease? Int J Epidemiol 2008; 37: 1204-8.
68. Tavani A, Gallus S, Negri E, La Vecchia C. Milk, dairy products, and coronary heart disease. J Epidemiol Community Health 2002; 56: 471-2.

69. Biong AS, Rebnord HM, Fimreite RL, Trygg KU, Ringstad J, Thelle DS, et al. Intake of dairy fat and dairy products, and risk of myocardial infarction: a case-control study. Int J Food Sci Nutr 2008; 59: 155-65.

70. Stahelin HB, Ritzel G. Effect of whey on plasma lipids. Int J Vitam Nutr Res 1979; 49: 229-30.

71. Agarwal BD, Sikka KK, Srivastava DK, Wali M. Effect of lactose on serum lipids in cases of coronary artery disease. J Indian Med Assoc 1980; 75: 153-6.

72. Goseki-Sone M, Maruyama R, Sogabe N, Hosoi T. Effects of dietary lactose on long-term high-fat-diet-induced obesity in rats. Obesity (Silver Spring) 2007; 15: 2605-13.

73. Ebringer L, Ferencik M, Krajcovic J. Beneficial health effects of milk and fermented dairy products - review. Folia Microbiol (Praha) 2008; 53: 378-94.

74. Andrade S, Borges N. Effect of fermented milk containing Lactobacillus acidophilus and Bifidobacterium longum on plasma lipids of women with normal or moderately elevated cholesterol. J Dairy Res 2009; 76: 469-74.

75. St-Onge MP, Farnworth ER, Jones PJ. Consumption of fermented and non-fermented dairy products: effects on cholesterol concentrations and metabolism. Am J Clin Nutr 2000; 71: $674-81$

76. Jenkins TC, McGuire MA. Major advances in nutrition: impact on milk composition. J Dairy Sci 2006; 89: 1302-10.

77. Seidel C, Deufel T, Jahreis G. Effects of fat-modified dairy products on blood lipids in humans in comparison with other fats. Ann Nutr Metab 2005; 49: 42-8.

\footnotetext{
*Lena Ohlsson

Laboratory of Gastroenterology and Nutrition

Department of Clinical Sciences, Medicine

BioMedical Centre BII

Lund University

SE-22I 84 Lund, Sweden

Tel: +46462220706

Fax: +4646184792

Email: Lena.Ohlsson@med.lu.se
} 